\title{
Critical Evaluation of Blood Volume Measurements during Hemodialysis
}

\author{
Judith J. Dasselaar $^{\mathrm{a}}$ Frank M. van der Sande ${ }^{\mathrm{b}}$ Casper F.M. Franssen ${ }^{\mathrm{a}}$ \\ aDivision of Nephrology, Department of Internal Medicine, University Medical Center Groningen, \\ Groningen, and bivision of Nephrology, Department of Internal Medicine, University Hospital Maastricht, \\ Maastricht, The Netherlands
}

\section{Key Words}

Blood volume · Fluid overload $\cdot$ Hemodialysis $\cdot$ Hypotension

\begin{abstract}
Devices that continuously measure relative blood volume (RBV) changes during hemodialysis (HD) are increasingly used for the prevention of dialysis hypotension and fine-tuning of dry weight. However, RBV measurements are subject to various limitations. First, RBV devices provide information on relative blood volume changes but not on absolute blood volume. Since blood volume varies with the hydration status, identical reductions of RBV may result in very different absolute blood volumes at the end of HD. Second, RBV changes underestimate the change of total blood volume due to translocation of lower-hematocrit blood from the microcirculation to the central circulation. Third, changes in posture before and during HD, food intake, exercise, and administration of intravenous fluids may influence the validity of the RBV measurement. Fourth, results obtained by various RBV devices show large interdevice differences. Finally, although a fall in blood volume is an important factor in dialysis hypotension, frank dialysis hypotension only occurs when the cardiovascular compensatory mechanisms can no longer compensate for the reduction in blood volume. Therefore, the dialysis staff should not exclusively focus on RBV, but also search for opportunities in the dialysis prescription
\end{abstract}

to facilitate cardiovascular compensatory mechanisms, e.g. by lowering dialysate temperature. In the opinion of the authors, routine RBV monitoring should be used with caution until the major conceptual and methodological problems that are inherent to the indirect RBV estimation are clarified.

Copyright $\odot 2012$ S. Karger AG, Basel

\section{Introduction}

Devices that noninvasively and continuously measure the change in relative blood volume (RBV) during hemodialysis (HD) are increasingly used for the prevention of dialysis hypotension and fine-tuning of dry weight [1-3]. The fall in blood volume during HD results from the imbalance between the ultrafiltration rate and the plasma refilling rate $[4,5]$. The use of the RBV devices is based on the optimistic belief that dialysis hypotension can be avoided as long as the RBV stays on the safe side of a critical individual threshold, and that postdialysis target weight is probably correct as long as the change in RBV follows an intermediate course that is neither flat or too steep $[6,7]$. These assumptions may be true at the population level, but, currently, evidence-based protocols on how to use RBV changes for the optimization of the dialysis prescription of the individual patient are lacking. Furthermore, the measurement of RBV is subject to con-

\section{KARGER}

Fax +4161306 1234

E-Mail karger@karger.ch

www.karger.com
(C) 2012 S. Karger AG, Basel

0253-5068/12/0333-0177\$38.00/0

Accessible online at:

www.karger.com/bpu
Casper F.M. Franssen, MD, PhD

Division of Nephrology, Department of Internal Medicine

University Medical Center Groningen

Hanzeplein 1, NL-9713 GZ Groningen (The Netherlands)

Tel. +31 50361 5497, E-Mail c.f.m.franssen@ int.umcg.nl 
ceptual, physiological, and technical limitations that the dialysis staff should keep in mind when using the course of RBV for the modification of the HD prescription. In this review we focus on the limitations of RBV measurements and briefly discuss studies on the use of RBV measurements for the prevention of dialysis hypotension and assessment of dry weight.

\section{Noninvasive Measurement of Changes in Blood Volume}

The classical way to measure plasma volume and red cell volume is by dilution techniques using, for instance, ${ }^{131}$ I-labeled human albumin and ${ }^{51} \mathrm{Cr}$-labeled red blood cells. However, these methods are impractical in clinical practice. The attractive aspect of noninvasive RBV monitoring devices is that they permit real-time RBV assessments during the entire HD session. These noninvasive techniques are based on the principle of mass conservation: the concentrations of blood constituents that are confined to the vascular space change proportionally as a result of changes in plasma volume. The change in RBV is calculated by the formula: $\mathrm{RBV}$ change (in \%) $=\left(\left(\mathrm{C}_{0} /\right.\right.$ $\left.\left.C_{t}\right)-1\right) \times 100$, with $C_{0}$ and $C_{t}$ representing the concentration of the blood constituent at the start and during $\mathrm{HD}$, respectively. Concentration changes of blood constituents only accurately reflect changes in blood volume if two assumptions are correct. First, the total amount of the constituent in the circulation must be constant. Second, there must be uniform mixing of the blood constituent throughout the vascular space. These prerequisites are not always met during HD as will be discussed below.

$\mathrm{RBV}$ monitors differ in the type of blood constituent that they use as a marker. Most devices that are currently used measure either hemoglobin or hematocrit, or the concentration of total plasma proteins (including hemoglobin). It is beyond the scope of this article to discuss the various devices in detail.

\section{Problems with the Measurement of RBV}

\section{Conceptual Limitation}

Noninvasive RBV devices provide information on relative blood volume changes, but give no information on the actual absolute blood volume. The absolute blood volume increases as the extracellular fluid volume increases both in healthy people [8] and in HD patients [9]. Therefore, the absolute blood volume at the start of HD is ex-

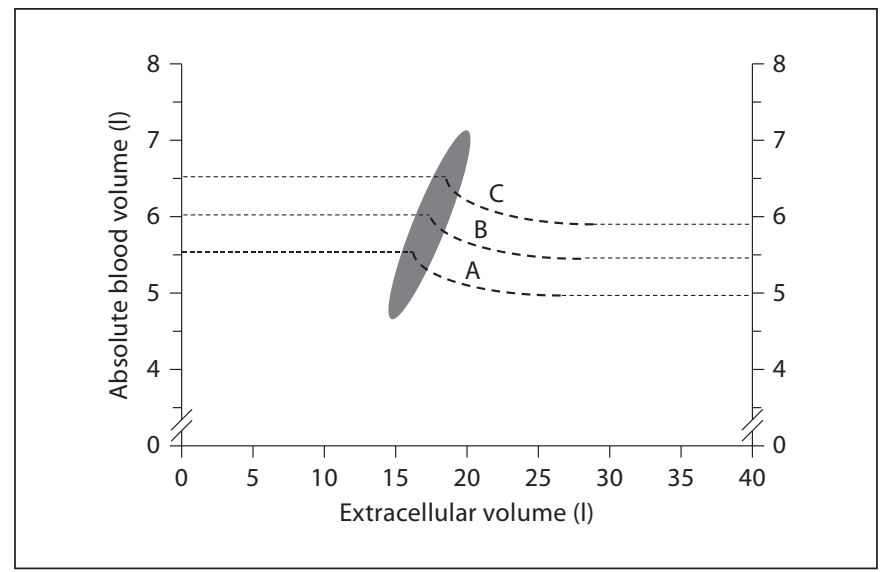

Fig. 1. The gray area shows the approximate relation between the extracellular fluid volume and blood volume (adapted from [8]). The curves A through C depict hypothetical blood volume courses in the same patient with varying predialysis hydration status. With varying extracellular fluid volume, this patient's absolute blood volume varies between 5.5 liters (A) and 6.5 liters (C). Although the decrease in the relative blood volume is $10 \%$ in all 3 curves, the residual absolute blood volume at the end of the HD session differs markedly.

tremely variable depending on the hydration status of the patient [10]. It follows that in the same patient, identical RBV decreases may result in very different postdialysis absolute blood volumes (fig. 1).

The hydration status itself also strongly influences the RBV course during HD: the less overhydrated the patient, the more pronounced the RBV decrease per unit of ultrafiltration volume due to a lower refill rate when the patient is closer to dry weight $[11,12]$.

\section{Intravascular Blood Volume Distribution}

Calculation of RBV changes from changes in blood constituents relies on the assumption that there is uniform mixing of red cells and plasma throughout the whole circulation. However, whole body hematocrit is lower than the hematocrit of the arterial or venous blood. The difference is due to a dynamic reduction in microvascular hematocrit in capillaries and venules $(<200$ $\mu \mathrm{m})$, known as the Fahraeus effect. The difference between the arterial or venous hematocrit and the whole body hematocrit is expressed as the F-cell ratio, i.e. the ratio of whole body hematocrit to arterial or venous hematocrit, and approximates 0.91 in nondialysis individuals. The lack of uniform mixing of erythrocytes throughout the circulation would not induce an error in the RBV calculation if the difference in hematocrit between the 
Fig. 2. Upper panel: course of total blood volume changes $(\triangle \mathrm{TBV} ; \circ)$ and $\mathrm{RBV}$ changes $(\Delta \mathrm{RBV} ; \bullet)$ during HD. Data represent the means \pm SD of 7 patients. ${ }^{*}$ Indicates $\mathrm{p}<$ 0.05 between the two curves. Lower panel: course of the F-cell ratio ( $\odot$ ) during HD. * Indicates $\mathrm{p}<0.05$ in comparison with the start of HD.

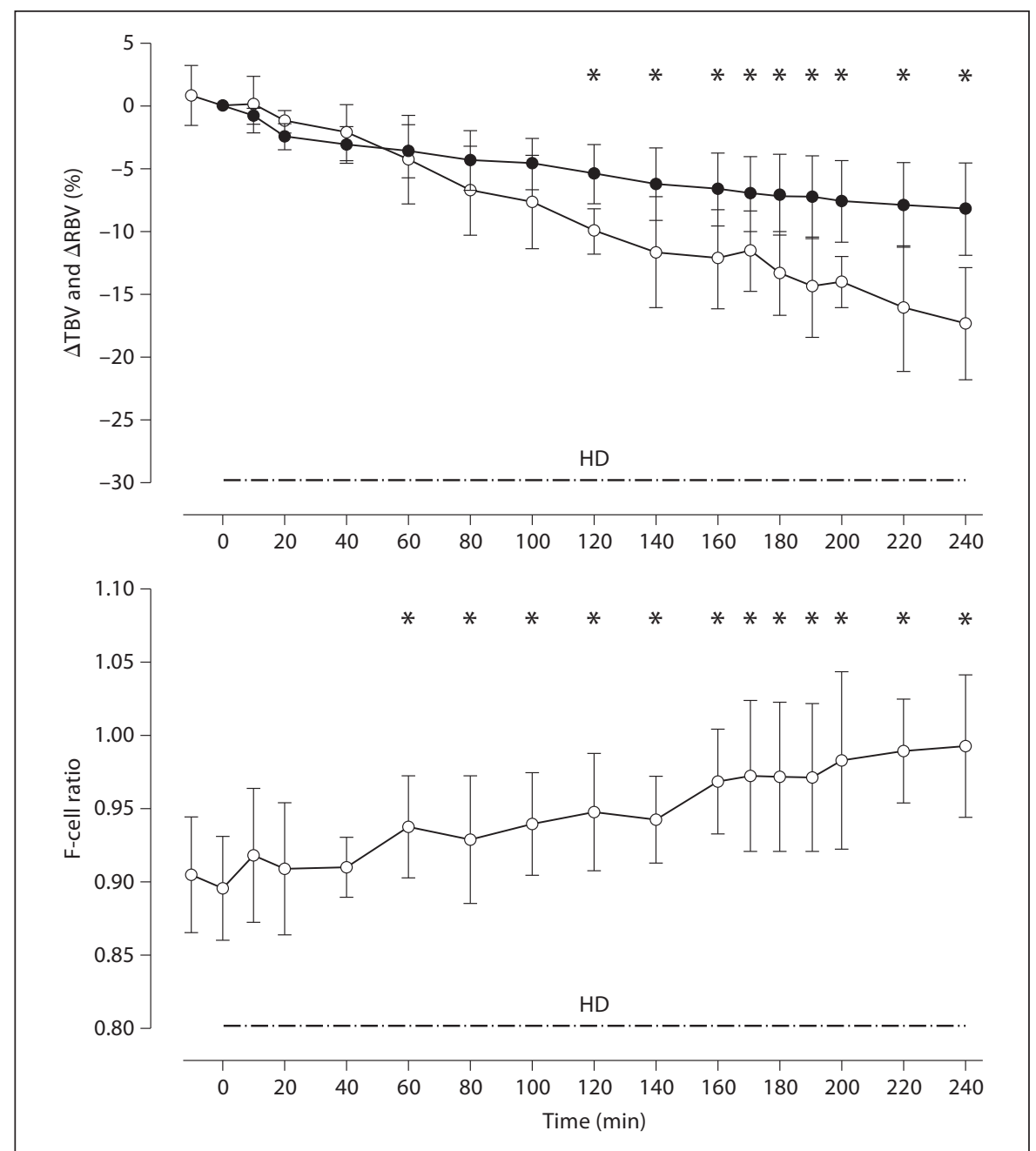

different vascular beds remained constant during HD; in other words, if the F-cell ratio would not change. In healthy individuals, exercise, heat stress, and long-term standing are all associated with an increase in the F-cell ratio, which reflects redistribution of blood from the microcirculation to the central circulation [13]. This intravascular translocation of blood is considered to be a cardiovascular compensatory mechanism to maintain central blood volume in order to compensate for a decrease in plasma volume. The intravascular translocation of blood in these circumstances negatively affects the validity of RBV reductions calculated from hemoglobin or hematocrit changes [13]. The consequence of blood translocation from the microcirculation to the central circulation is that the observed decrease in RBV in the mixed arterial/venous blood will underestimate the reduction of the total blood volume [14]. Recently, we showed by direct measurement of absolute plasma volume $\left({ }^{125} \mathrm{I}\right.$ and ${ }^{123} \mathrm{I}$ radio-ionated albumin) and erythrocyte volume $\left({ }^{51} \mathrm{Cr}-\right.$ labeled erythrocytes) that the fall in RBV significantly underestimated the decrease in total blood volume (fig. 2) [15].

\section{Factors That May Influence the Validity of RBV Measurements}

Postural changes have a profound effect on plasma volume in healthy subjects [16] and in HD patients [17]. Upon standing, the hematocrit increases because of a decrease in plasma volume due to a fluid shift from the circulation to the interstitial tissue of the dependent regions of the body. Resumption of the supine body position after standing facilitates mixing of blood between the circulatory compartments and leads to a rapid and marked temporary increase in hematocrit followed by a slow decrease 
[16]. Inagaki et al. [17] found that hemodilution and, thus, the fluid flux from the interstitial tissue to the vascular space took more time $(>30 \mathrm{~min})$ in $\mathrm{HD}$ patients than healthy controls ( $<15 \mathrm{~min})$. Many patients assume a supine or half-sitting position just before the start of HD (e.g. for connection of a central venous access) after a period of standing. The RBV device uses the first measurement as the reference value to calculate subsequent RBV changes. However, at the time the reference value is being measured there will often be no steady state of the concentrations of the blood constituents due to the preceding postural change. Postural changes during HD such as resumption of the Trendelenburg position may also have a profound effect on hemoglobin and hematocrit [18].

Other factors that may influence the course of RBV include food intake, intradialytic exercise, and intravenous administration of erythrocytes or albumin containing fluids during HD. These factors are discussed in detail in Dasselaar et al. [19].

\section{Technical Limitations}

We have previously compared the results from three different RBV devices (Crit-line, BVM, and Hemoscan) with the change in RBV calculated from changes in laboratory-derived hematocrit and found that the different devices yielded RBV results that differed systematically from those calculated from laboratory-derived hemoglobin changes. Furthermore, we observed substantial differences in the RBV change between the different devices [20]. It follows that the results from these devices should be considered as an estimate of 'real' RBV changes and that results of different devices are not interchangeable.

\section{The Fall in Blood Volume Is Not the Only Factor in Dialysis Hypotension}

Although the initiating factor in the pathogenesis of dialysis hypotension is a decrease in blood volume, frank dialysis hypotension only occurs when the cardiovascular compensatory mechanisms can no longer compensate for the reduction in blood volume $[4,5]$. The major cardiovascular compensatory mechanisms are a reduction of the venous capacity by venoconstriction of the capacitance vessels, active increases in arterial tone, and increases in heart rate and contractility [5]. Structural cardiovascular changes such as left ventricular hypertrophy and diastolic dysfunction also play important roles since these conditions oppose ventricular filling and, thus, pre- dispose to an early fall in end-diastolic volume and stroke volume during $\mathrm{HD}$, causing hypotension.

The compensatory mechanisms are affected by several patient and treatment factors, e.g. ambient and dialysate temperature and food intake. The compensatory mechanisms can also be stimulated, e.g. by enhancing venous and arteriolar vasoconstriction by lowering dialysate temperature [21].

\section{Clinical Studies}

Relation between RBV Changes and Intradialytic Hemodynamic Stability

Randomized studies on the value of RBV measurements in order to prevent dialysis hypotension are lacking. Several observational studies, however, have linked RBV changes with the course of intradialytic blood pressure and the occurrence of dialysis hypotension. Only a minority of these studies demonstrated a relationship between RBV and the development of dialysis hypotension [22], whereas most studies did not find a significant association [23-28]. In particular, one of the largest observational studies demonstrated that the maximal RBV reduction during the HD session had no power in predicting hypotensive episodes [23]. In that study, no critical individual RBV reduction level for the appearance of symptomatic hypotension could be found. Interestingly, irregularity of the RBV course was the most powerful predictor of intradialysis hypotension [23]. In another study, it was not the magnitude of the RBV reduction, but the switch from an exponential to a linear decrease of the RBV that predicted intradialytic hypotension [27]. To date, one study has explored the relation between the RBV course and blood pressure in patients with acute renal failure in the intensive care unit [28]. In that study there was no relation between RBV course and intradialytic blood pressure.

There are some studies in which the dialysis prescription was modified by 'nurse-driven' adaptations of the ultrafiltration rate and/or infusion of intravenous fluids in response to the observed RBV changes as a means to reduce the frequency of dialysis hypotension $[1,29,30]$. These relatively small studies showed that adapting the ultrafiltration rate based on observed RBV changes has a positive effect in diminishing intradialytic hypotension $[1,29,30]$. Alternatively, automatic biofeedback systems have been developed that modify certain treatment parameters in response to RBV changes; however, the discussion of these studies is beyond the scope of this article. 


\section{$R B V$ Changes for the Modification of Dry Weight}

Some studies have addressed the question whether monitoring of RBV changes is useful for assessing dry weight $[6,7,31]$. This is based on the notion that patients who are overhydrated have higher plasma refill rates and, as a consequence, their RBV slope may be flat. Patients with a low plasma refill rate will have steeper RBV slopes and are more likely to be at their 'dry weight' [32]. In the largest study to date, this was indeed true on the population level [7]. Importantly, the RBV slopes predicted the subsequent reduction in ambulatory blood pressure after reducing dry weight [7]. However, whether the RBV slope is indeed useful for the modification of dry weight in individual patients is presently unknown.

\section{Conclusions and Recommendations}

In the opinion of the authors, routine RBV monitoring in clinical practice should be used with caution until the major methodological and conceptual problems inherent to indirect blood volume estimation are clarified. The limitations of the use of these devices should be known to the complete dialysis staff. In addition, practical guidelines should be developed on how to interpret and use the $\mathrm{RBV}$ results generated by these devices in the individual patient. Of course, future studies should take into account the relationship between RBV changes and (residual) absolute blood volume and the change in F-cell ratio during $\mathrm{HD}$, and attempt to standardize all factors that are known to influence the RBV course as much as possible. At the same time, the wide availability of the RBV devices facilitates further research on the relationship between RBV changes and intradialytic hemodynamic stability, which will hopefully lead to a better understanding of the pathophysiology of dialysis hypotension.

\section{Disclosure Statement}

J.J.D. and C.F.M.F. have received an unrestricted research grant from Gambro-Hospal in 2004. In addition, they have written study material for this company.

\section{References}

1 Steuer RR, Leypoldt JK, Cheung AK, Senekjian HO, Conis JM: Reducing symptoms during hemodialysis by continuously monitoring the hematocrit. Am J Kidney Dis 1996;27:525-532.

-2 Basile C: Should relative blood volume changes be routinely measured during the dialysis session? Nephrol Dial Transplant 2001;16:10-12.

$\checkmark 3$ De Vries JP, Donker AJ, De Vries PM: Prevention of hypovolemia-induced hypotension during hemodialysis by means of an optical reflection method. Int J Artif Organs 1994;17:209-214.

4 van der Sande FM, Kooman JP, Leunissen KM: Intradialytic hypotension - new concepts on an old problem. Nephrol Dial Transplant 2000;15:1746-1748.

$\checkmark 5$ Daugirdas JT: Pathophysiology of dialysis hypotension: an update. Am J Kidney Dis 2001;38:S11-S17.

6 Lopot F, Kotyk P, Blaha J, Forejt J: Use of continuous blood volume monitoring to detect inadequately dry weight. Int J Artif Organs 1996;19:411-414

7 Sinha AD, Light RP, Agarwal R: Relative plasma volume monitoring during hemodialysis aids in the assessment of dry weight. Hypertension 2009;55:305-311.

8 Guyton A, Hall J: Textbook of Medical Physiology. Philadelphia, Saunders, 2000, p 332. $\checkmark 9$ Movilli E, Cancarini G, Cassamali S, Camerini C, Brunori G, Maffei C, Maiorca R: Inter-dialytic variations in blood volume and total body water in uraemic patients treated by dialysis. Nephrol Dial Transplant 2004; 19:185-189.

10 Santoro A, Mancini E: Clinical significance of intradialytic blood volume monitoring. Int J Artif Organs 1997;20:1-6.

$\checkmark 11$ Koomans H, Geers A, Mees E: Plasma volume recovery after ultrafiltration in patients with chronic renal failure. Kidney Int 1984; 26:848-854.

12 Wizeman V, Leibinger A, Mueller K, Nilson A: Influence of hydration state on plasma volume changes during ultrafiltration. Artif Organs 1995;19:416-419.

$>13$ Lee S: Microvascular volume changes induced by exercise, heat exposure, or endotoxin injection. Am J Physiol Heart Circ Physiol 1994;267:H1142-H1150.

14 Mitra S, Chamney P, Greenwood R, Farrington $\mathrm{K}$ : The relationship between systemic and whole-body hematocrit is not constant during ultrafiltration on hemodialysis. J Am Soc Nephrol 2004;15:463-469.

15 Dasselaar JJ, Lub-de Hooge MN, Pruim J, Nijnuis H, Wiersum A, de Jong PE, Huisman RM, Franssen CF: Relative blood volume changes underestimate total blood volume changes during hemodialysis. Clin J Am Soc Nephrol 2007;2:669-674.
16 Lundvall J, Bjerkhoel P: Pronounced and rapid plasma volume reduction upon quiet standing as revealed by a novel approach to the determination of the intravascular volume change. Acta Physiol Scand 1995;154: 131-142.

17 Inagaki H, Kuroda M, Watanebe S, Hamazaki T: Changes in major blood components after adopting the supine position during haemodialysis. Nephrol Dial Transplant 2001; 16:798-802.

18 Steuer R, Harris D, Conis J: Instantaneous changes in circulating blood volume due to various physiological maneuvers. Dial Transplant E-Neph Arch 1994;23:643-646.

19 Dasselaar JJ, Huisman RM, de Jong PE, Franssen CFM: Relative blood volume measurement during hemodialysis - merits and limitations. Nephrol Dial Transplant 2005; 20:2043-2049.

20 Dasselaar JJ, de Jong PE, Huisman RM, Franssen CF: Relative blood volume measurements during hemodialysis, comparisons between three non-invasive devices. Hemodialysis Int 2007; 11:448-455.

-21 Van der Sande FM, Wystrychowski G, Kooman JP, Rosales L, Raiman J, Kotanko P, Carter M, Chan CT, Leunissen KM, Levin NW: Control of core temperature and blood pressure stability during hemodialysis. Clin J Am Soc Nephrol 2009;4:93-98. 
-22 De Vries JP, Kouw PM, van der Meer NJ, Olthof CG, Oe LP, Donker AJ, de Vries PM: Non-invasive monitoring of blood volume during hemodialysis: its relation with postdialytic dry weight. Kidney Int 1993;44:851854.

-23 Andrulli S, Colzani S, Mascia FLucchi L, Stipo L, Bigi MC, Crepaldi M, Redaelli B, Albertazzi A, Locatelli F: The role of blood volume reduction in the genesis of intradialytic hypotension. Am J Kidney Dis 2002;40: 1244-1254.

-24 Maeda K, Morita H, Shinzato T, Vega BV, Kobayakawa $\mathrm{H}$, Ishihara $\mathrm{T}$, Inagaki $\mathrm{H}$, Igarashi I, Kitano T: Role of hypovolemia in dialysis-induced hypotension. Artif Organs 1988; $12: 116-121$.
5 Krepel HP, Nette RW, Akcahuseyin E, Weimar W, Zietse R: Variability of relative blood volume during haemodialysis. Nephrol Dial Transplant 2000;15:673-679.

26 Oliver MJ, Edwards LJ, Churchill DN: Impact of sodium and ultrafiltration profiling on hemodialysis-related symptoms: J Am Soc Nephrol 2001;12:151-156.

27 Mitra S, Chamney P, Greenwood R, Farrington $\mathrm{K}$ : Linear decay of relative blood volume during ultrafiltration predicts hemodynamic instability. Am J Kidney Dis 2002;40 556-565.

28 Tonelli M, Astephen P, Andreou P, Beed S, Lundrigan P, Jindal K: Blood volume monitoring in intermittent hemodialysis for acute renal failure. Kidney Int 2002;62:1075-1080.

-29 Stiller S, Wirtz D, Waterbar F, Gladziwa U, Dakshinamurty KV, Mann H: Less symptomatic hypotension using blood volume controlled ultrafiltration. ASAIO Trans 1991;37:M139-M141.
30 Ishihara T, Igarashi I, Kitano T, Shinzato T, Maeda K: Continuous hematocrit monitoring method in an extracorporeal circulation system and its application for automatic control of blood volume during artificial kidney treatment. Artif Organs 1993;17:708-716.

31 Steuer RR, Germain MJ, Leypoldt JK, Cheung AK: Enhanced fluid removal guided by blood volume monitoring during chronic hemodialysis. Artif Organs 1998;22:627632 .

32 Agarwal R: Relative plasma volume monitoring for identifying volume-sensitive and -resistant hypertension. Semin Dial 2010;5: 462-465. 